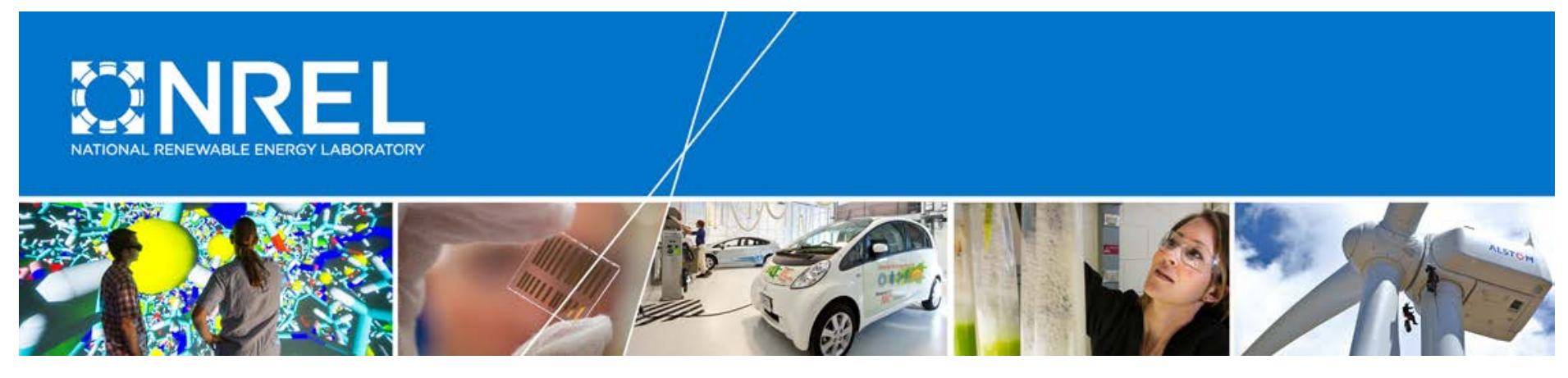

\title{
Optimal Sizing of a Solar-Plus- Storage System For Utility Bill Savings and Resiliency Benefits
}

\section{Preprint}

Travis Simpkins, Kate Anderson, Dylan Cutler, and Dan Olis National Renewable Energy Laboratory

Presented at the Seventh Conference on Innovative Smart Grid Technologies (ISGT2016)

Minneapolis, Minnesota

September 6-9, 2016

(C) 2016 IEEE. Personal use of this material is permitted. Permission from IEEE must be obtained for all other uses, in any current or future media, including reprinting/republishing this material for advertising or promotional purposes, creating new collective works, for resale or redistribution to servers or lists, or reuse of any copyrighted component of this work in other works.

NREL is a national laboratory of the U.S. Department of Energy Office of Energy Efficiency \& Renewable Energy Operated by the Alliance for Sustainable Energy, LLC

This report is available at no cost from the National Renewable Energy Laboratory (NREL) at www.nrel.gov/publications.

\section{Conference Paper}

NREL/CP-7A40-66088

November 2016 


\section{NOTICE}

The submitted manuscript has been offered by an employee of the Alliance for Sustainable Energy, LLC (Alliance), a contractor of the US Government under Contract No. DE-AC36-08GO28308. Accordingly, the US Government and Alliance retain a nonexclusive royalty-free license to publish or reproduce the published form of this contribution, or allow others to do so, for US Government purposes.

This report was prepared as an account of work sponsored by an agency of the United States government. Neither the United States government nor any agency thereof, nor any of their employees, makes any warranty, express or implied, or assumes any legal liability or responsibility for the accuracy, completeness, or usefulness of any information, apparatus, product, or process disclosed, or represents that its use would not infringe privately owned rights. Reference herein to any specific commercial product, process, or service by trade name, trademark, manufacturer, or otherwise does not necessarily constitute or imply its endorsement, recommendation, or favoring by the United States government or any agency thereof. The views and opinions of authors expressed herein do not necessarily state or reflect those of the United States government or any agency thereof.

This report is available at no cost from the National Renewable Energy Laboratory (NREL) at www.nrel.gov/publications.

Available electronically at SciTech Connect http:/www.osti.gov/scitech

Available for a processing fee to U.S. Department of Energy and its contractors, in paper, from:

U.S. Department of Energy

Office of Scientific and Technical Information

P.O. Box 62

Oak Ridge, TN 37831-0062

OSTI http://www.osti.gov

Phone: 865.576.8401

Fax: 865.576.5728

Email: reports@osti.gov

Available for sale to the public, in paper, from:

U.S. Department of Commerce

National Technical Information Service

5301 Shawnee Road

Alexandria, VA 22312

NTIS http://www.ntis.gov

Phone: 800.553 .6847 or 703.605 .6000

Fax: 703.605.6900

Email: orders@ntis.gov 


\title{
Optimal Sizing of a Solar-Plus-Storage System For Utility Bill Savings and Resiliency Benefits
}

\author{
Travis Simpkins, Kate Anderson, Dylan Cutler, Dan Olis \\ National Renewable Energy Laboratory \\ Golden, CO, USA \\ travis.simpkins@nrel.gov
}

\begin{abstract}
Solar-plus-storage systems can achieve significant utility savings in behind-the-meter deployments in buildings, campuses, or industrial sites. Common applications include demand charge reduction, energy arbitrage, time-shifting of excess photovoltaic production, and selling ancillary services to the utility grid. These systems can also offer some energy resiliency during grid outages. It is often difficult to quantify the amount of resiliency that these systems can provide, however, and this benefit is often undervalued or omitted during the design process. We propose a method for estimating the resiliency that a solar-plus-storage system can provide at a given location. We then present an optimization model that can optimally size the system components to minimize the lifecycle cost of electricity to the site, including the costs incurred during grid outages. The results show that including the value of resiliency during the feasibility stage can result in larger systems and increased resiliency.
\end{abstract}

Keywords-batteries, energy storage, mathematical programming, microgrids, photovoltaic systems

\section{INTRODUCTION}

As component and installation costs have decreased, solar photovoltaic (PV) systems are now economically viable in many parts of the world. Many expect the costs of energy storage to follow a similar trajectory, leading to a rapid uptake in deployment over the next several years. There is significant interest in pairing solar PV with energy storage as it can unlock many synergies between the technologies.

A battery, for example, can allow excess PV production during the afternoon to be shifted to the evening, thus avoiding the need to sell electricity back to the grid, perhaps at an unfavorable rate. Batteries can also be strategically discharged to smooth the PV production and, therefore, more consistently reduce peak demand charges. Batteries can be used for energy arbitrage, in which they are charged overnight at off-peak rates and discharged during the day when electricity prices are higher. In some locations, battery owners may be compensated for providing ancillary services, which help to stabilize the utility grid.
Solar-plus-storage systems may also offer some measure of resiliency during grid outages when the installation includes hardware capable of forming and operating a microgrid. While many of the functions solar-plus-storage systems can provide result in real cash savings or payments to the owners, the value of the resiliency benefit is harder to quantify. The challenge is that it involves both determining the costs incurred by a customer when they lose electricity and assessing the amount of resiliency that a solar-plus-storage system can provide, which is an inherently stochastic analysis owing to the variability of the solar resource and the electrical load profile. For these reasons, energy resiliency is often not explicitly valued during the techno-economic analysis for the project; any resiliency achieved is simply a byproduct rather than a design objective.

In this paper we discuss the meaning of resiliency in solarplus-storage systems, propose a simulation methodology for quantifying the resiliency that such systems may provide, and then present an optimization model that is capable of determining the optimal sizing and dispatching of a solar-plusstorage system for utility bill savings and increased resiliency. Finally, we present results for techno-economic analysis of a solar-plus-storage system on a building in New York City.

\section{DEFINING RESILIENCY}

An energy resilient building, campus, or community is one that is able to adapt to disruptions of the electrical grid such that it can continue to operate during periods when the primary grid has failed. Such resiliency has traditionally been provided by backup diesel generators, which are restricted to only operating during outages. Solar-plus-storage systems, in contrast, can operate for economic gain during normal grid operation, while also providing backup power when the grid has failed. It is important to characterize the resiliency that a solar-plus-storage system may provide, and that is the focus of this section.

The resiliency provided by a solar-plus-storage system is fundamentally different than that provided by a diesel generator. Assuming that the generator was sized 
appropriately relative to the load, and that it starts and functions properly when commanded, it can be reasonably assumed to provide sufficient electricity to meet the load until its fuel reserves are depleted. The operating duration of such a system is, therefore, limited only by availability of fuel.

In contrast, the resiliency offered by a solar-plus-storage system, particularly one that was sized predominantly for economic reasons, is less predictable; the battery may be in the midst of a peak shaving application when the outage occurs and thus not fully charged, or a partially cloudy day may only allow the PV array to meet part of the electrical load. As a result, the resiliency that a solar-plus-storage system provides may be considered to be of lower quality than that of a diesel generator, and thus the customer may be unwilling to pay as much to obtain it. It still provides some benefit, however, and for sites where solar-plus-storage systems are on the verge of becoming financially viable, the incremental value of resiliency, small is it may be, could be enough to economically justify the project.

\section{A. Estimating the Resiliency of a Solar-Plus-Storage System}

The amount of time for which a solar-plus-storage system can sustain an electrical load during a grid outage is proportional to the solar resource, electrical load being served, and the state of charge of the battery at the time the outage occurs. This means that the duration for which the system can sustain the load will vary depending on the time of day, or season of the year, that the outage starts. For example, the system may be able to sustain the load for a longer period of time if the outage starts at noon on a sunny day than if it begins at night. The amount of time that the system can sustain the load is, therefore, a random variable.

To characterize the random variable, we performed a series of nested-loop simulations to calculate the number of hours that a PV-battery system could sustain the load for outages beginning during every hour $[h]$ of the year. For an outage beginning in the first hour of the year $[h=1]$, we first tested whether the system could sustain the load using the electricity produced by the PV array, battery discharges, or a combination. If it could, we updated the state of charge of the battery (including charging, if there was excess PV production) and proceeded to test the next hour $[h+1]$. This process continued through subsequent hours $[h+t]$ until the system was no longer able to meet the load. The number of hours, $t$, that the system could sustain the load for an outage beginning in hour $\mathrm{h}$ was recorded. At this point the state of charge of the battery was reset to the maximum, and the same process was repeated for the second hour of the year $[h=2]$ and all subsequent hours through the end of the year $[h=$ 8760]. The result was a vector indicating the number of hours that the solar-plus-storage system could maintain the load for an outage beginning in that hour.

In our model, the average of the resiliency vector is then the number of hours that the solar-plus-storage can be expected to maintain the load for a randomly occurring grid outage. We define this resiliency metric $R$.

Fig. 1 shows a representative plot of the resiliency vector for a $10 \mathrm{~kW}$ PV array paired with a $30 \mathrm{kWh}$ : $10 \mathrm{~kW}$ battery when used to sustain a given load at a particular location. The average amount of resiliency that this system provides, $R$, is 5.2 hours. This ranges from a high of 22 hours when conditions are favorable in the spring, to a low of 0 hours during the summer. In contrast, the resiliency $R$ of a diesel generator for this site may be eight hours with little, if any, variation over the course of the year.

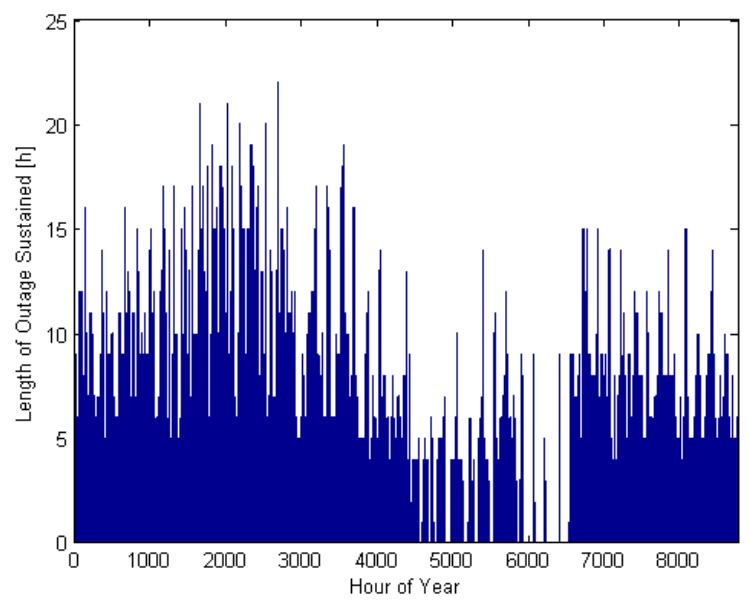

Fig. 1. Number of hours a $10 \mathrm{~kW} \mathrm{PV}$ and $30 \mathrm{kWh}: 10 \mathrm{~kW}$ battery can sustain the load for outages starting at every hour of the year.

\section{B. Valuing the Resiliency Benefit of Solar-Plus-Storage}

The Customer Average Interruption Duration Index, CAIDI, describes the average outage duration that a customer can expect to experience in a year [1]. An annual cost of interruption, $A C I$, can then be found by multiplying the $C A I D I$ by the hourly cost of grid interruptions, $C G I$, as follows

$$
A C I=C A I D I \times C G I
$$

The CGI varies widely depending on the function of the building. Critical facilities such as hospitals or data centers may have very high costs of interruption, while less critical facilities may have low costs. There are a variety of methods to estimate this cost ranging from detailed site surveys [2], [3] to higher level market studies [4]-[7]. For this analysis, the $C G I$ was estimated based on national survey data for medium and large commercial and industrial customers [8].

The ACI can be reduced or eliminated if there is a backup source of power to sustain the electrical load during outages. If the backup power has perfect reliability, the hourly resiliency benefit derived by the customer each year, $R B$, may be equal to the $C G I$. Otherwise, as in the case of a solar-plus-storage system, it may be de-rated by some factor $\alpha$ owing to uncertainty in $R$. This can be expressed as

$$
\alpha \times R \times R B<=A C I
$$

As an example, if $C A I D I$ is equal to two hours, the $R$ for a system is two hours, and an arbitrary $\alpha$ of $50 \%$ is applied, the $A C I$ will only be reduced by $50 \%$ instead of being eliminated completely even though the resiliency metric indicates that the system should be able to sustain the average outage. 


\section{MODEL DESCRIPTION}

We implemented a linear program to simultaneously optimize component sizing for a behind-the-meter solar-plusstorage system for both utility bill reduction and increased resiliency. This optimization model was based on our REopt modeling platform for energy system integration and optimization [9].

The model is based on the principle of energy balance such that the electrical load is met in every time step by a combination of grid purchases, PV production, or battery discharge. The model then minimizes the lifecycle cost of electricity to the site, including financial losses incurred during grid outages. Transient effects and the flow of power between nodes in the network are not considered.

The model is capable of operating at various temporal resolutions, with the computational complexity increasing with increasing resolution. The analysis period is typically 25 years. The model solves the energy balance for the first year and then assumes that the same conditions persist in each of the following years. Utility costs, including both energy and demand charges, are found by first escalating the present costs at an appropriate inflation rate, and then discounting them back to the present.

\section{A. Objective Function}

The objective of the optimization model is to minimize the present value of all future energy costs over the analysis period, including the capital costs and maintenance costs of PV and batteries, the costs and revenues associated with buying from and selling electricity to the grid, incentives and tax benefits, and financial losses incurred due to grid outages. This can be formulated as

Minimize $\sum$ Present Value [Capital Costs + Maintenance

+ Energy Purchases + Demand Charges + Losses Due to Outages - Energy Sellback - Incentives - Tax Benefits]

where

$$
\text { Losses Due to Grid Outages }=A C I-\alpha \times R B \times R
$$

and

$$
R<=C A I D I
$$

which prevents the model from deriving a higher value from resiliency than can typically be used in a given year. In cases where the $R B$ has been de-rated as described in Section II, it will be less than the cost of interruptions, and as such the system will not be able to fully eliminate the $A C I$. $R$ is then defined as

$$
x_{1} \times s_{1}+x_{2} \times s_{2}
$$

where $s_{1}$ and $s_{2}$ are the sizes of the PV array and the battery energy capacity, respectively, and $x_{1}$ and $x_{2}$ are regression coefficients obtained after calculating a range of $R$ values for various component sizes at a particular location (as described in Section II) and then performing a multi-variable regression analysis on the results.

\section{B. Candidate Technologies}

The primary decision variables are the size of the PV array and the size of the battery, including both its energy capacity and power rating. The model also solves for the optimal dispatch strategy at every time step for each of the candidate technologies that it chooses to build.

1) Utility Grid: The utility grid is effectively assumed to be an ideal source of electricity capable of supplying infinite amounts of electricity. Since it already exists, the model does not incur any capital costs for using the grid, nor is there any maintenance cost associated with it.

The costs to acquire electricity from the grid are divided into usage costs and demand charges. The model pays for each unit [kWh] of electricity it uses at a rate specified by the tariff. Peak demand charges are also described by the tariff and are based on the largest grid purchase within the hours comprising a particular demand ratchet. The model can accommodate any number of demand ratchets throughout the year. Common examples include peak and off-peak demand periods each day, with the hours associated with each period changing seasonally.

2) Photovoltaics: The model can choose to build PV and, therefore, incur an initial capital cost in the present in exchange for free electricity in the future. The amount of electricity produced by a PV array in a given hour is proportional to the hourly solar capacity factor for the location and is obtained from PVWATTS [10]. The production of PV arrays tends to decline over their lifespan, yet the model solves for only one year; therefore, the geometric mean output of all of the years is assumed, rather than the first year production.

The size of the PV array can vary up to the user-defined maximum, which is commonly limited by the roof or land area available. The capital cost is based upon the rated capacity $[\mathrm{kW}]$ of the PV array and includes the present value of any incentives, rebates, and tax benefits such as accelerated depreciation. A PV array is expected to last 25 years with periodic maintenance, the costs of which are included in the model. The associated inverter is likely to need to be replaced once during that time, and the replacement cost is amortized into the annual maintenance costs.

The model determines the size of PV to build, if any, as well as how to dispatch the electricity produced during every hour to minimize the cost of electricity to the site. That is, the model decides whether to use the PV electricity to serve the load directly, to charge a battery if one exists, to sell it back to the grid-either at an export rate or at the retail rate if a net energy metering agreement is in place-or to curtail it. The size of the PV system is a continuous decision variable.

3) Battery Energy Storage: Batteries are devices capable of moving electricity that is produced (or purchased) during one hour to a future hour, albeit with a small loss. In a linear program, it is not necessary to specify the battery application a priori. Instead, the model is allowed to determine the best use of the battery to minimize the cost of electricity at the site by deciding when to charge it, whether to charge it from excess PV production or the grid, and when to discharge it. 
That means that the dispatch strategy for the battery can change from day to day, or even hour to hour, based on what is most cost economical.

The amount of energy that the battery can store is determined by its capacity [kWh] while the rate at which it charges or discharges is determined by its power rating $[\mathrm{kW}]$. Different ratios of power to energy are preferable for different applications, and since each is an independent decision variable, the model is able to choose the ratio that minimizes the electricity costs to the site. The capital cost for batteries includes a separate cost for both power and energy, the combined total of which represent the cost of the battery.

We do not explicitly model battery chemistries but rather impose some heuristic constraints that are designed to ensure that the battery is operated within the manufacturer's specifications. For example, the model is required to keep lithium ion batteries above $20 \%$ state of charge and is slightly biased to keep them at a higher state of charge when not in use. Furthermore, the round trip efficiency can be varied based on the battery type.

A lithium ion battery may be expected to last perhaps ten years based on the calendar degradation model [11], [12]. Therefore when a battery is paired with PV in a solar-plusstorage application it may need to be replaced at the midlife of the project. We accommodate this in the model by amortizing the replacement cost into the upfront capital cost. A battery may not last the entire ten years, however, if it experiences an excessive number of deep charge / discharge cycles. Rather than include this effect in the model, we simply assume that the battery will last ten years, based on calendar degradation, and then post-process the dispatch using the rainflow algorithm [13], [14] to verify the assumption.

\section{RESULTS}

The model was used to optimally size a solar-plus-storage system for a building in New York City. The building had an average electrical load of $15.2 \mathrm{~kW}$, with a minimum of $2.9 \mathrm{~kW}$ and a maximum of $63.2 \mathrm{~kW}$. There was space for as much as $30 \mathrm{~kW}$-DC of PV on the roof. The rate tariff included an energy charge of $\$ 0.048$ per $\mathrm{kWh}$ in summer (June September) and $\$ 0.043$ per $\mathrm{kWh}$ in winter, and a monthly demand charge of $\$ 32.63$ per $\mathrm{kW}$. There was no existing backup generation. The site currently spends $\$ 17,988$ on electricity each year, including $\$ 6,042$ on energy, and $\$ 11,946$ on demand charges. The 25-year lifecycle cost of electricity is therefore $\$ 283,333$, assuming a discount rate of $6 \%$ and an inflation rate of $2 \%$. This increases to $\$ 287,400$ when the costs of grid outages are included.

PV was assumed to have an installed cost of $\$ 3.00$ per Watt-DC and to be eligible for a 30\% Investment Tax Credit as well as the 5-year MACRS tax benefit. The annual maintenance cost for a PV system is assumed to be $\$ 20$ per $\mathrm{kW}$ per year escalating at the general inflation rate.

The battery was assumed to cost $\$ 600$ per kWh and $\$ 1000$ per $\mathrm{kW}$, meaning, for example, that a $30 \mathrm{kWh}: 10 \mathrm{~kW}$ battery would cost $\$ 28,000$. The round-trip efficiency was assumed to be $92.5 \%$.
The regression coefficients for the resiliency expression were found using by performing parametric sweeps of the system sizes and recording $R$ for each combination as described in Section II. The PV system was swept from 0 to $20 \mathrm{~kW}$ and the battery from 0 to $40 \mathrm{kWh}$. For simplicity, we assumed a three-hour battery $(\mathrm{C} / 3)$ battery such that the energy capacity was triple the power rating in every case. Figure 2 shows the variation of $R$ with PV size and battery capacity. The multi-variable regression analysis resulted in coefficients of 0.0038 and 0.039 for $x_{1}$ and $x_{2}$, respectively, with a coefficient of determination $\left(\mathrm{R}^{2}\right)$ of 0.82 .

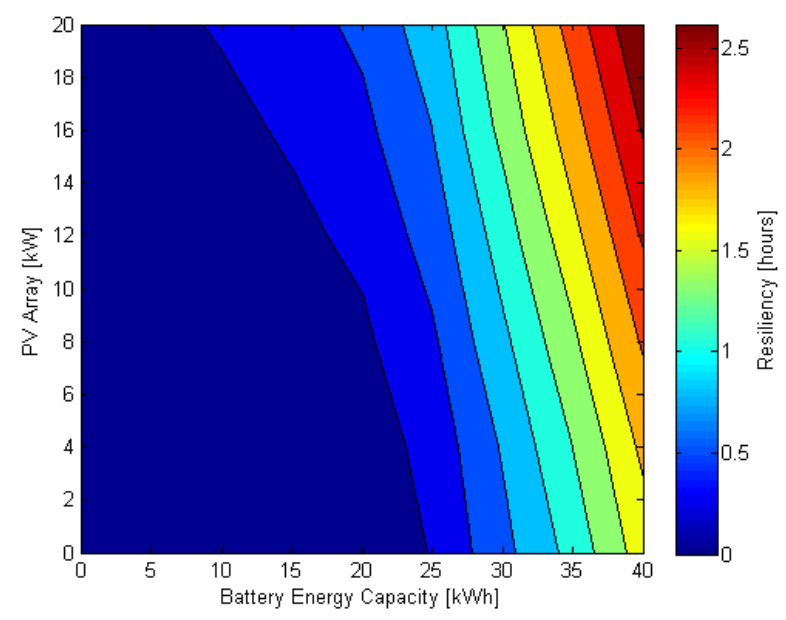

Fig. 2. Resiliency provided by solar-plus-storage systems of varying size.

The system was first optimized to minimize the lifecycle cost of energy to the site without valuing the resiliency benefit of the system. This resulted in a $11.3 \mathrm{~kW}$ PV system and a $14.2 \mathrm{kWh}: 8.1 \mathrm{~kW}$ battery with a lifecycle cost of $\$ 266,638$ and, when the lifecycle cost is subtracted from the base case lifecycle cost, a net present value of $\$ 16,695$. Though no value was placed on resiliency, the $R$ of the system was calculated to be 0.38 hours.

The system was then re-optimized with the value of the resiliency benefit included. The CAIDI for the utility was 1.8 hours [15] and the CGI was estimated at $\$ 286$ per hour, resulting in an $A C I$ of $\$ 515$ per year. We arbitrarily de-rated the value of the resiliency benefit by $50 \%$ for a solar-plusstorage system to $\$ 143$ per hour with a maximum of $\$ 257$ per year, as described in Section II.

As shown in Table I, when resiliency was valued at $\$ 143$ per hour, the size of the solar-plus-storage system increased. The PV system increased by $19 \%$ to $13.4 \mathrm{~kW}$ while the battery capacity increased by $31 \%$ to $18.6 \mathrm{kWh}$, and the battery power rating increased by $15 \%$ to $10.2 \mathrm{~kW}$. The larger solar-plusstorage system can sustain the critical load for 0.78 hours, an increase of $105 \%$ compared to the smaller system. The lifecycle cost of the system was $\$ 269,071$. This indicates that if the resiliency benefit is included during the feasibility analysis, system owners may build larger solar-plus-storage systems, resulting in systems that can sustain the load for longer duration outages. 
TABLE I. Optimal System Sizes With and Without Valuing RESILIENCY

\begin{tabular}{|l|c|c|}
\hline & $\begin{array}{c}\text { Resiliency Benefit } \\
\text { Valued at \$0 / hour }\end{array}$ & $\begin{array}{c}\text { Resiliency Benefit } \\
\text { Value at \$143 / hour }\end{array}$ \\
\hline PV Size & $11.3 \mathrm{~kW}$ & $13.4 \mathrm{~kW}$ \\
\hline Battery Size & $14.2 \mathrm{kWh}: 8.1 \mathrm{~kW}$ & $18.6 \mathrm{kWh}: 9.3 \mathrm{~kW}$ \\
\hline Life Cycle Cost & $\$ 266,638$ & $\$ 269,071$ \\
\hline Net Present Value & $\$ 16,695$ & $\$ 14,262$ \\
\hline Resiliency (hours) & 0.38 & 0.78 \\
\hline
\end{tabular}

We then then repeated the optimization while progressively increasing the value placed on resiliency. Fig. 3 shows that the optimal component sizes of a PV battery system (top) and the amount of resiliency that the system provides (bottom) both increase as the price that the customer is willing to pay for the resiliency benefit increases.
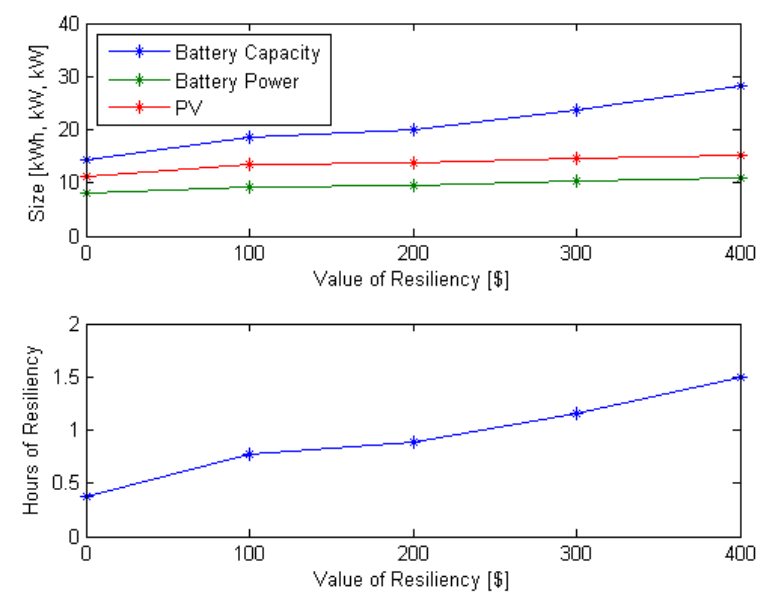

Fig. 3. Optimal system sizes and the hours of resiliency provided both increase as the value of resiliency increases.

\section{DISCUSSION AND CONCLUSION}

We considered the value of sustaining operations during short duration outages as would typically be represented by CAIDI. There is, of course, also value in sustaining longer duration outages, but the analysis of resiliency during catastrophic events was not included. We assumed that the entire load needed to be met during every hour of the grid outage, and defined $R$ as the average number of hours that the system was able to do so. Other possible definitions of $R$ could include the number of hours that a critical load can be met, or the fraction of hours that a partial load could be met, thus recognizing that solar-plus-storage systems may not be able to sustain the load continuously, but may be able to provide intermittent power. This latter case would derive significant value during catastrophic outages.

In conclusion, this paper has shown that the optimal sizes of components and the amount of resiliency that they provide increase as the value assigned to resiliency is increased. While the value of resiliency on its own may not justify installation of a solar-plus-storage system, this analysis indicates that, in some cases, including the value of resiliency alongside other value streams may lead system owners to install larger solarplus-storage systems. In future work, we plan to expand the model to include other potential revenue streams such as selling ancillary services to the grid.

\section{ACKNOWLEDGMENT}

The authors gratefully acknowledge the City University of New York and the New York Department of Citywide Administrative Services for providing data for the building in New York City, and our colleagues Kari Burman, Shivani Mathur, Lars Lisell , Emma Elgqvist, and Joyce McLaren.

\section{REFERENCES}

[1] IEEE Power Engineering Society. 2004. IEEE Std 1366:-2003 IEEE Guide for Electric Power Distrubtion Reliability Indices. ISBN 0-73813890-8 SS95193. New York: Institute of Electrical and Electronics Engineers, Inc. May 14.

[2] M.J. Sullivan and D.M. Keane, "Outage Cost Estimation Guidebook," EPRI Research Project 2878-04 Final Report, December 1995.

[3] J. Giraldez, S. Booth, K. Anderson, and K. Massey, "Valuing Energy Security: Customer Damage Function Methodology and Case Studies at DoD Installations," NREL Report No. TP-7A30-55913, National Renewable Energy Laboratory, Golden, CO, 2012.

[4] R. Billinton "Economic cost of non-supply." IEEE Power Engineering Society Winter Meeting. Vol. 2, 2002; pp. 959-962.

[5] M. De Nooij, C. Koopmans, and C. Bijvoet, "The value of supply security: The costs of power interruptions: Economic input for damage reduction and investment in networks," Energy Economics (29:2), 2007; pp. 277-295.

[6] J. Rao, P. Prasad, and G. Das, "Customer outage cost evaluation in electric power systems." ARPN Journal of Engineering and Applied Sciences (5:8), August 2010; pp. 88-96.

[7] D. Lineweber and S. McNulty, The Cost of Power Disturbances to Industrial \& Digital Economy Companies: Submitted to EPRI's Consortium for Electric Infrastructure for a Digital Society. Madison, WI: Primen, 2001

[8] M.J. Sullivan, J. Schellenberg, and M. Blundell, "Updated Value of Service Reliability Estimates for Electric Utility Customers in the United States," Lawrence Berkeley National Laboratory, San Francisco, CA, Tech. Rep. LBNL-6941E, Jan. 2015.

[9] T. Simpkins, D. Cutler, K. Anderson, D. Olis, E. Elgqvist, M. Callahan, and A. Walker, "REopt: A Platform for Energy System Integration and Optimization," in Proc. $8^{\text {th }}$ International Conf. on Energy Sustainability, Boston, MA, 2014.

[10] T. Simpkins, D. Cutler, B. Hirsch, D. Olis, and K. Anderson, "CostOptimal Pathways to $75 \%$ Fuel Reduction in Remote Alaskan Villages," in Proc. Conf. on Technologies for Sustainability, Ogden, Utah, 2015

[11] A.P. Dobos, "PVWatts Version 1 Technical Reference," NREL Report No.TP-6A20-60272, National Renewable Energy Laboratory, Golden, $\mathrm{CO}$.

[12] H.J. Ploehn, R. Premanand, and R.E.White, "Solvent diffusion model for aging of lithium-ion battery cells," J. Echem. Soc. (2004) 151 (3) A456-A462 3.

[13] M. Safari and C. Delacourt, "Simulation-based analysis of aging phenomena in a commercial graphite/LiFePO4 cell," J. Echem. Soc. (2011) 158 (12) A1436-1447

[14] S.D. Downing, and D.F. Socie, "Simple rainflow counting algorithms," International Journal of Fatigue; 1982.

[15] C.H. McInnes and P.A. Meehan, "Equivalence of four-point and threepoint rainflow cycle counting algorithms," International Journal of Fatigue; 2007.

[16] Con Edison 2014 Sustainability Report. http://www.conedison.com/ehs/2014-sustainabilityreport/files/Print_Customized_Report\%20_\%20Con_Edison_2014_Sus tainability_Report.pdf. 